\title{
PI in STM resulting from the semantic similarity of items'
}

ARTHUR E. WHIMBEY and VALERIE FISCHHOF, California State College at Hayward, Hayward, California

Two experiments were performed to test the hypothesis that semantic similarity does not give rise to interference in STM. In both experiments a Peterson and Peterson type of STM task was used in which the Ss were required to recall three words after some intervening activity. All Ss were required to recall three sets of words. The last set was the critical test series and was identical for the experimental and the control groups. However, for the experimental group the first two series were semantically similar to the test series, whereas the control group had semantically dissimilar items. In both experiments the control group showed better recall than the experimental group, indicating that semantic similarity does in fact give rise to PI in STM.

Baddeley \&ale (1966) have presented data indicating that interference in LTM is a function of the semantic similarity of items whereas interference in STM results from acoustic similarity. Based on this data Adams (1967) has questioned Melton's (1963) conclusion that STM and LTM are continuous. Although hoth systems are subject to interference, interference in STM appeared to be based solely on acoustic similarity and therefore Adams concluded that STM and LTM are separate storage systems. Actually Baddeley and Dale did find a tendency for semantic similarity to produce PI in STM but the effect did not quite reach statistical significance. In the present experiments STM tasks which differed from that of Baddeley and Dale were used to make a further test of the conclusion that semantic similarity does not produce interference in STM.

Method

\section{EXPERIMENT}

The memory task used was similar to a task used previously by Peterson \& Peterson (1959). The Ss were told that three words would be read followed by seven 2-digit numbers presented at a $1 / \mathrm{sec}$ rate. The Ss were to listen to the words, write down the seven numbers as they were presented, and then try to recall and write the three words in order. Both the experimental and the control group were presented three sets of words and numbers. For the experimental group the three sets of words were: (1) bull, panther, red; (2) horse, lion, blue; and (3) cow, tiger, green. The control group was presented the sets: (1) house, book, chair; (2) fork, tree, ear; and (3) cow, tiger, green.

The Ss were group tested. The E said "ready" and then read the words at a $1 / \mathrm{sec}$ rate. The $\mathrm{E}$ then immediately said "now please write the following numbers" and the numbers were read. This was followed by the statement "now please write the three words in order" and $10 \mathrm{sec}$ were allowed for recall. The Ss were then instructed to place the answer sheet on the bottom of the pile of six sheets which had been given each $S$ at the beginning of the experiment, and the presentation-recall sequence was repeated.

At the beginning of the experiment the Ss were instructed not to try to rehearse the words while writing the numbers since it would result in a number being missed. A practice trial consisting of the words, radio, store, and soda preceded the experiment proper.

The Ss were students taking a course in introductory psychology. There were 24 and 18 Ss in the experimental and control groups respectively.

Results and Discussion

In order to test for interference resulting from semantic similarity a comparison was made of the number of Ss in the experimental and the control group who correctly recalled the three words which were presented in the last series, namely, the words cow, tiger, and green. Of the 24 Ss in the experimental group 13 Ss recalled the three words correctly. For the control group 15 of the 18 Ss recalled the words correctly. A chi square test was run and the proportions $(13 / 24$ and $15 / 18)$ were found to be significantly different $\left(x^{2}=3.94, p<.05\right)$.

The results indicate that the experimental group was more susceptible to PI from previous items than the control group. Since the previous items for the experimental group were more similar to the test items than were the previous items for the control group the data indicate that semantic similarity does affect PI in STM.

In order to insure that the difference between the groups was not produced by the specific words used in Experiment 1, a second experiment was performed using different words and a slightly different experimental procedure.

\section{EXPERIMENT 2}

\section{Method}

The Ss were 18 students in an introductory course in psychological statistics. Nine Ss served in the experimental group and nine served in the control group. The Ss were instructed that three words from the same conceptual category would be presented followed by 10 two-digit numbers. For the experimental group the three sets of words were (1) white, yellow, blue; (2) purple, black, red; and (3) green, pink, orange. The control group was presented the words (1) lion, tiger, panther; (2) chair, table, sofa; and (3) green, pink, orange. The practice trial for both groups consisted of the words, woman, girl, lady. The remainder of the instructions and procedure were identical to that used in Experiment 1 except for one other modification. The Ss wery instructed that after the numbers were presented they would either be asked to recall the three words mentally but would be told not to write the words, or they would be asked to recall and write the three words. In fact, the words were recalled mentally on the practice trial and the first two series and were written only on the third series.

Results and Discussion

In the control condition eight of the nine Ss recalled the final series correctly, whereas in the experimental condition only five of the nine Ss recalled the series. This difference is in the predicted direction, although it was not statistically significant because of the small $\mathrm{n}$.

Both experiments support the conclusion that semantic similarity does give rise to PI in STM. The memory tasks used in the present experiments differed from the one used by Baddeley and Dale in a number of ways (e.g., inter- vs intra-list interference, response vs stimulus similarity) which might account for the greater PI found in the present experiment. But it appears that even in STM the conceptual category of the response may be recalled in some form and those members which have been primed by recent exposure are remembered. Previous items from the same conceptual category intrude overtly, or intrude covertly, either completely or partially, and produce errors.

\section{REFERENCES}

ADAMS, J. A. Human memory. New York: McGraw-Hill, 1967.

BADDELEY, A. O., \& DALE, H. C. A. The effect of semantic similarity on retroactive interference in long- and short-term memory. Journal of Verbal Learning \& Verbal Behavior, 1966, 5, 417-420.

MELTON, A. W. Implications of short-term memory for a general theory of memory. Journal of Verbal Learning \& Verbal Behavior, 1963, 2, 1-21.

PETERSON, L. R., \& PETERSON, M. J. Short-term retention of indjidual verbal items. Journal of Experimental Psychology, 1959, 58, 193-198. NOTE

1. This research was supported in part by Small Grant OEG 1.7.070028-5239 from The Office of Education, Bureau of Research. 